\title{
Medio-Lateral Hamstring Muscle Activity in Unilateral vs. Bilateral Strength Exercises in Female Team Handball Players - A Cross- Sectional Study
}

\author{
Brian Sørensen, PT, MSc ${ }^{1}$, Per Aagaard, PhD², Lasse Malchow-Møller, MSc ${ }^{3}$, Mette Kreutzfeldt Zebis, PhD ${ }^{4}$, Jesper \\ Bencke, $\mathrm{PhD}^{3}$ a \\ ${ }^{1}$ Human Movement Analysis Laboratory, Dept. of Orthopaedic Surgery, Copenhagen University Hospital Amager-Hvidovre, Hvidovre, Denmark; \\ Department of Sports Science and Clinical Biomechanics, Research Unit for Muscle Physiology and Biomechanics, University of Southern Denmark, 2 \\ Department of Sports Science and Clinical Biomechanics, Research Unit for Muscle Physiology and Biomechanics, University of Southern Denmark, 3 \\ Human Movement Analysis Laboratory, Dept. of Orthopaedic Surgery, Copenhagen University Hospital Amager-Hvidovre, Hvidovre, Denmark, 4 \\ Department of Midwifery, Physiotherapy, Occupational Therapy and Psychomotor Therapy, Faculty of Health, University College Copenhagen, \\ Copenhagen, Denmark \\ Keywords: strength, medio-lateral activation, hamstrings, exercise, emg \\ https://doi.org/10.26603/001c.24150
}

\section{International Journal of Sports Physical Therapy}

Vol. 16, Issue 3, 2021

\section{Background}

Reduced activation of the hamstring muscles and specifically the medial semitendinosus muscle (ST) has been shown to be a risk factor for non-contact anterior cruciate ligament (ACL) injury. Specific hamstring strength exercises may show high ST activity, however the effect of unilateral vs. bilateral exercise execution on ST activation remains unknown.

\section{Purpose}

To investigate selected lower limb strengthening exercises performed either unilaterally or bilaterally to identify 1 ) which exercise elicited the highest hamstring activation, 2) which exercise elicited the highest ST activation, and 3) to examine if unilateral exercise execution altered the medio-lateral hamstring activation pattern. Furthermore, the kinematic characteristics of each specific exercise and execution modality were determined to reveal possible causes for differences in medio-lateral hamstring activation between the different exercise conditions.

\section{Study design}

Cross-sectional study.

\section{Methods}

Single-session repeated measures were obtained in a randomized manner. Twenty-three female elite team handball players were recruited. Hamstring electromyographic (EMG) activity and 3D kinematics were obtained during selected lower limb exercises (hip thrust, kettlebell swing, Romanian deadlift). Hamstring EMG activity, normalized to maximal voluntary contraction (MVC) (nEMG), and inter-muscular activation difference between the ST and lateral hamstring biceps femoris (BF) were compared across exercises using two-way repeated measures ANOVA.

\section{Results}

Bilateral hip thrust demonstrated highest overall hamstring activity (68.9 $\pm 16.6 \%)$. Kettlebell swing $(\Delta 13 \%$-point, $\mathrm{p}<0.01)$ and Romanian deadlift $(\Delta 20-24 \%$-point, $\mathrm{p}<0.01)$ demonstrated greater ST-BF activation differences $(\Delta=\mathrm{ST}-\mathrm{BF})$ in favor of ST compared to 
hip thrust ( $\Delta 2-7 \%)$. Positive correlations were observed between knee joint angle and ST activity in kettlebell swing and deadlift.

\section{Conclusion}

Kettlebell swing, deadlift and hip thrust all produced high activation of the hamstring muscles. Kettlebell swing and both deadlift exercises were superior in activating ST over $\mathrm{BF}$, favoring these exercises in the prevention of non-contact ACL injury in female athletes, which should be evaluated in future intervention studies.

\section{Level of evidence}

\section{INTRODUCTION}

Acute knee injuries, especially to the ACL, often result in functional instability. ${ }^{1}$ Consequently, ACL injury can have a number of negative consequences on both the short- and long-term functioning of the knee joint. ${ }^{2-4}$

ACL injuries occur three to seven times more frequently in athletes compared to non-athletes, and represents a substantial problem in ball sports such as team handball and football, ${ }^{5-8}$ which involve sudden stops and side-cutting maneuvers. In $80 \%$ of the cases, the ACL injury happens in non-contact situations. ${ }^{9}$ Further, the incidence of non-contact ACL injury is reported to be three to six times higher for women than men. ${ }^{3,9-13}$ Proper neuromuscular control is imperative for stabilization of the knee joint during athletic movements with injury risk. Especially, adequate hamstring activation before or during the landing phase is considered important to control excessive rotations and protect e.g. the ACL. ${ }^{11,12,14}$

Compared to male athletes, female athletes exhibit greater quadriceps EMG activity during vertical stop-jump tasks $^{14}$ and side-cutting maneuvers, ${ }^{15,16}$ while male athletes often display higher hamstring activation in these situations with high risk of ACL injury. ${ }^{14-22}$ Moreover, reduced strength and recruitment of the hamstring muscles are considered significant risk factors in relation to noncontact ACL-rupture. ${ }^{23-25}$ Introducing preventive training programs have shown positive effects on the musclestrength relationship between quadriceps and the hamstrings, ${ }^{22,24}$ as well as on the neuromuscular activation pattern in selected landing and side-cutting situations. ${ }^{22}$ The medial hamstring muscle(s) seem particularly important in this context, as a reduced medial (semitendinosus) electromyographic (EMG) activity during side-cutting in combination with a high activity in the lateral quadriceps (vastus lateralis) have been shown to be related to an elevated risk of non-contact ACL injury. ${ }^{25}$ Previous research has identified dynamic valgus of the knee as a predisposing factor for ACL injury in female athletes. ${ }^{26}$ The balance between medial-lateral hamstring recruitment seems highly important for the control of dynamic valgus. ${ }^{27}$ Female athletes appear to have disproportionately greater EMG activity in their lateral biceps femoris muscle than male athletes when landing from a jump. ${ }^{28}$ Increased lateral hamstring recruitment potentially could lead to a more open medial joint space and thereby contributing to increased dynamic valgus, and hence contribute to increase the risk of non-contact ACL injury. ${ }^{28}$

Strengthening exercises for the hamstring muscles such as hip extension and isolated knee flexion (i.e. leg curl) typically show high levels of muscle activity in the lateral biceps femoris compared to the medial semitendinosus. ${ }^{29-33}$ From an ACL injury prevention perspective, it thus becomes relevant to examine the relative balance between semitendinosus and biceps femoris muscle activity during commonly used training exercises, in order to identify or develop exercises with high medial vs lateral hamstring muscle activity. Recent research has identified the Kettlebell swing and Romanian deadlift to be associated with a preferential activity in the semitendinosus vs. biceps femoris muscle, ${ }^{33,34}$ and as a common characteristic both exercises are performed with nearly straight knees and a forceful hip extension with the peak load at the most flexed hip joint angle. However, these exercises may vary in the technique, load and intensity of the movement, which may affect the activity of the muscles. Furthermore, progression in these exercises are frequently achieved by using a single stance leg, typically in a common belief that the preventive exercise effect is improved when the exercise involves an increased need for dynamic joint stabilization. However, the effect of this assumption on hamstring muscle activation levels has never been tested in controlled experimental settings.

The purpose of this study, therefore, was to investigate selected lower limb strengthening exercises performed either unilaterally or bilaterally to identify 1) which exercise elicited the highest hamstring activation, 2) which exercise elicited the highest ST activation, and 3) to examine if unilateral exercise execution altered the medio-lateral hamstring activation pattern. Furthermore, the kinematic characteristics of each specific exercise and execution modality were determined to reveal possible causes for differences in medio-lateral hamstring activation between the different exercise conditions.

\section{METHODS}

\section{SUBJECTS}

Female team handball players from the three highest Danish team handball divisions were invited to participate in the study. Twenty-three players (mean age: $20.7 \pm 2.9$ year; mean height: $176.0 \pm 5.7 \mathrm{~cm}$; mean weight: $73.1 \pm 7.3 \mathrm{~kg}$; mean handball training frequency: $3.2 \pm 0.9$ sessions/week; mean strength training frequency: $2.8 \pm 0.8$ sessions/week) with no previous history of ACL injury or hamstring injury volunteered to participate in the study.

The study was approved by the local Ethics Committee (H-18063645). All participants received written information 
about the study and each participant confirmed their participation by signing a written declaration of consent. All participants were informed about the protection of subject rights.

\section{TEST PROCEDURES}

A pretest familiarization session was carried out on a separate day prior to the first test day. In this session, all experimental exercises were demonstrated for the participant by an experienced test instructor. Afterwards the participant executed the exercises with guidance from the test instructor to ensure that the exercise was correctly executed. When correct technique and movement execution were achieved, the individual load for the testing day was established for each exercise. The kettlebell weight corresponded to a 20RM load, whereas an 8RM load was chosen for the bilateral Romanian deadlift and hip thrust exercises. During all unilateral exercise conditions, the exercise load/ weight corresponded to half of the load used in the corresponding bilateral exercise condition.

On the day of testing, all participants performed a standardized warm-up program that involved five stretching exercises for the larger muscle groups (quadriceps, hamstrings, chest, shoulders, back) followed by a number of low-load strength training exercises (squats, lunges, hip bridge, back extensions, crunches, push-ups) performed in 3 sets of 10 repetitions for each exercise with 30-45 s rest between sets. After warm-up, participants performed three maximal voluntary isometric knee flexor contractions (MVC) of five seconds duration (30-s pause between successive MVC trials) were performed to determine maximal volitional EMG activity in the lateral and medial hamstring muscles (more details provided below). Finally, for familiarization ten repetitions were performed for each exercise using a 16RM load (40RM in kettlebell swing) altogether followed by three minutes of rest. Subsequently, five test repetitions using an 8RM load (20RM load in kettlebell swing) were performed and sampled for later off-line analysis. A total of six exercises were performed in a cluster randomized order using lottery notes with numbers from 1 to 6 . The unilateral exercises were performed on both legs (and data averaged between the two limbs), in the order of dominant non-dominant leg. Approximately three minutes of rest were prescribed between exercises to avoid fatigue.

\section{EXERCISE PROTOCOL}

The exercise protocol involved three distinct lower limb strengthening exercises (kettlebell swing, Romanian deadlift and hip thrust). The exercises were selected based on their regular involvement in clinical practice and athlete physical conditioning, as well as being inspired by previous ACL injury prevention programs. ${ }^{29,35-41}$ As a common characteristic, all selected exercises involved a large degree of hip flexion and -extension.

\section{KETTLEBELL SWINGS (KS)}

Participants were standing with their feet positioned in parallel (shoulder width distance between right and left foot).

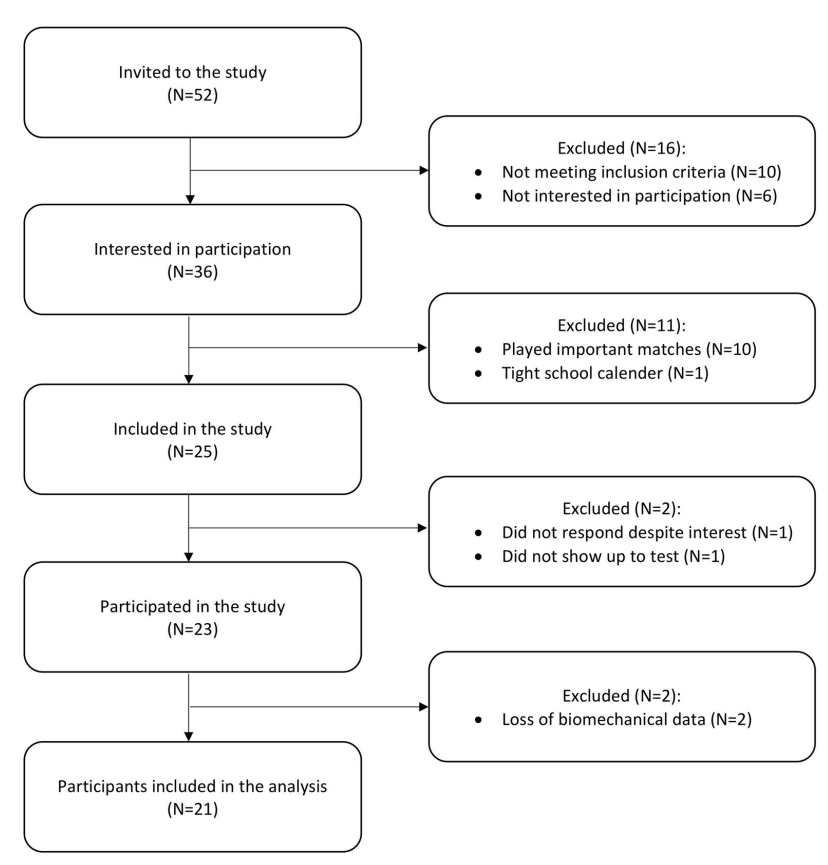

Figure 1: Flow-chart of participants

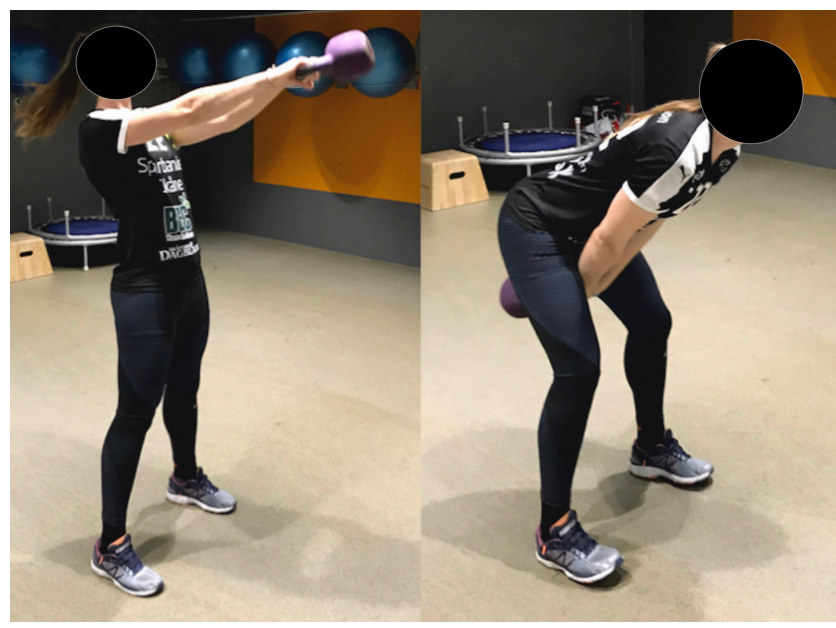

Figure 2A: The kettlebell swing

The exercise was always performed bilaterally (no unilateral variant) using an explosive (i.e. maximally accelerated) hip extension to swing the kettlebell up (chest level) using straight arms continuing into a down-ward swing between the legs, while in all swing phases maintaining a knee joint angle close to full extension (Figure 2A).

The kettlebell weight corresponded to a 20RM load i.e. the maximal weight the subject could swing 20 times without loss of correct technique. The subject performed a single set of ten swings using this load.

\section{ROMANIAN DEADLIFT (DL)}

Bilateral DL: Participants lifted the barbell (load corresponding to 8RM) with the feet parallel and shoulder-width apart. The barbell was lifted from hanging right below the 
knees with an explosive extension of the hips until standing upright (Figure $2 \mathrm{~B})$. The knees were maintained at an angle near full extension.

Unilateral DL: Participants performed the exact same movement as described for the bilateral DL, except standing on one leg. The subject performed a single set of five repetitions with a load corresponding to half of the two-legs load (Figure 2C).

\section{HIP THRUSTS (HT)}

Bilateral HT: Participants were positioned supine with the upper part of the back supported on a bench and starting with flexed hips and knees. A barbell was placed on the upper part of the thigh (weight corresponding to 8RM) and was lifted as fast as possible by extending the hips. The exercise was performed using two different feet positions that resulted in different knee joint angles at full hip extension; first, a set of five repetitions with an $\sim 90^{\circ}$ knee angle (Fig$\underline{\text { ure } 2 \mathrm{D}})$ and afterwards a set with $\sim 110^{\circ}$ knee angle $\left(180^{\circ}=\right.$ full extension).

Unilateral HT: This exercise was performed as described above for bilateral HT testing, except using a single leg only. The subject performed a single set of five repetitions with a weight corresponding to half of the load used in the twolegs HT (Figure 2E). Unilateral HT was only performed as the $90^{\circ}$ knee flexion end-position exercise.

\section{ELECTROMYOGRAPHY (EMG) RECORDINGS}

The skin of the subject was shaved with a hand razor and carefully cleaned with ethanol before electrode placement on both legs. Bipolar surface EMG electrodes (2-cm inter electrode distance, Myon Aktos, prophysics SOL AB, Höör, Sweden) were placed at the BF and ST muscles according to standard recommendations. ${ }^{42}$ Raw EMG signals were preamplified, band-pass filtered (20-450 Hz) and sampled with a frequency of $1000 \mathrm{~Hz}$. The EMG recordings were high-pass filtered using a $4^{\text {th }}$ order Butterworth filter with a cut-off frequency of $10 \mathrm{~Hz}$ and subsequently smoothed by a symmetrical moving root-mean-square filter (RMS) with a window size of $30 \mathrm{~ms}$ and $29 \mathrm{~ms}$ running overlap.

Before exercise testing, the maximal EMG activity was obtained during maximal voluntary isometric hamstring muscle contraction (MVC), as described in detail elsewhere. ${ }^{41}$ Three maximal isometric MVC's were performed for the knee flexors (hamstrings) of each leg separated by 30-s rest and the peak EMG amplitude of the three trials was used for later EMG normalization. ${ }^{41}$

All dynamic EMG data were normalized to the maximal EMG amplitude recorded during MVC testing. ${ }^{41}$ The peak EMG amplitude for each repetition was obtained, and the mean of five repetitions for DL and HT exercises, 33,43 and ten repetitions in KS for each participant were used. 33,41

\section{BIOMECHANICAL ANALYSIS}

All tests were performed in a biomechanical motion analysis laboratory with eight infrared cameras (Vicon T40 cameras, Vicon Motion Systems Ltd, Oxford, UK) with a frame capture frequency of $100 \mathrm{~Hz}$. Data were collected using in-

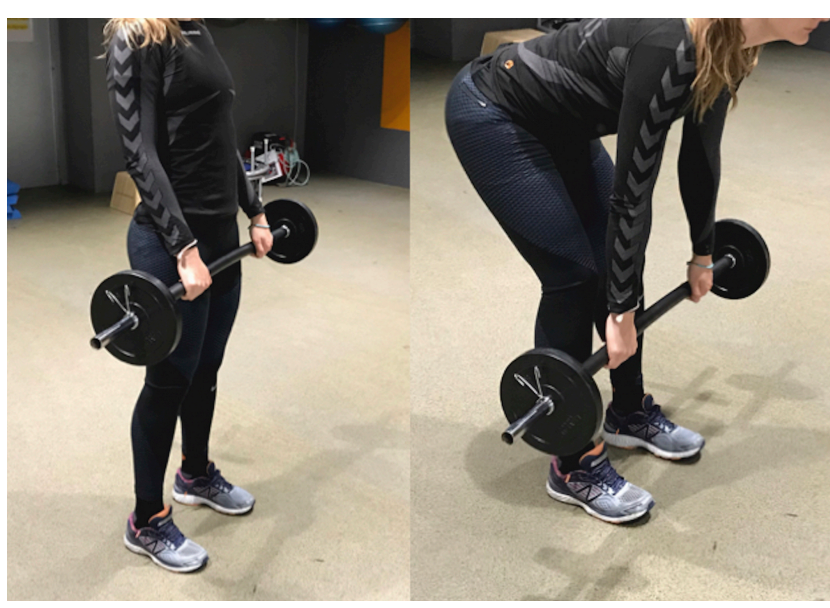

Figure 2B: Two legged dead lift

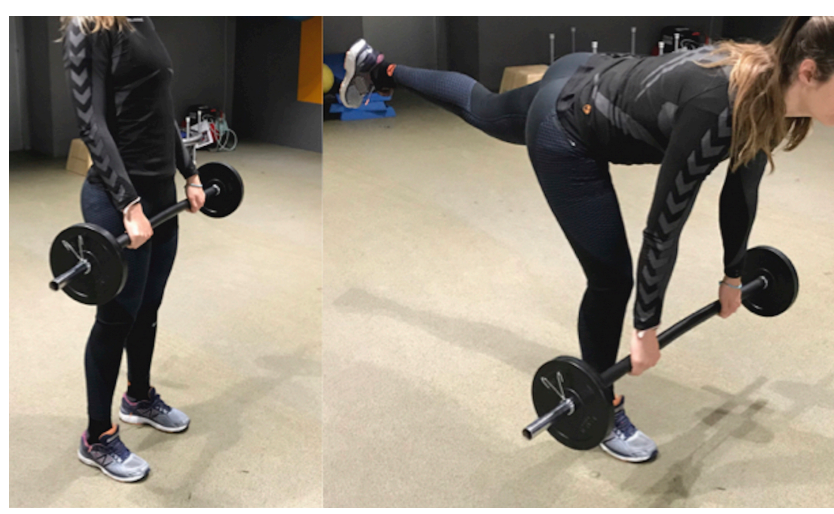

Figure 2C: Single leg deadlift

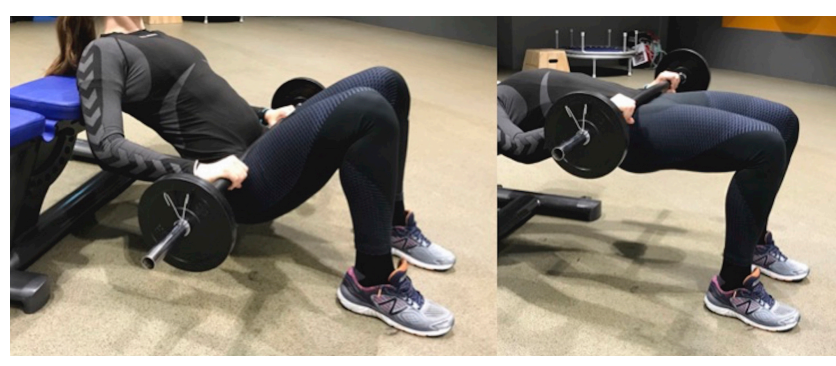

Figure 2D: Bilateral hip thrust

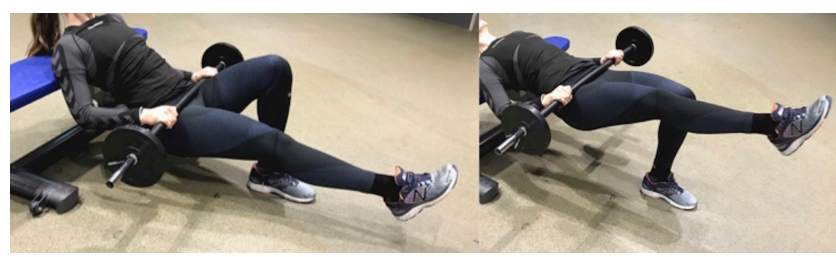

Figure 2E: Unilateral hip thrust

herent software, (Nexus 2, Vicon Motion Systems Ltd, Oxford, UK). 
Table 1: Descriptive characteristics of participants

\begin{tabular}{|l|c|c|c|c|}
\hline & $\mathrm{N}$ & Minimum & Maximum & Mean $( \pm$ SD) \\
\hline Age $(\mathrm{y}):$ & 23 & 18 & 28 & $20.7 \pm 2.9$ \\
Height $(\mathrm{cm}):$ & 23 & 165.7 & 190.8 & $176.0 \pm 5.7$ \\
Weight $(\mathrm{kg}):$ & 23 & 62.0 & 91.2 & $73.1 \pm 7.3$ \\
Active handball years: & 23 & 5 & 21 & $12.2 \pm 3.9$ \\
Handball training sessions per week: & 23 & 2 & 5 & $3.2 \pm 0.9$ \\
Strength training sessions per week: & 23 & 2 & 5 & $2.8 \pm 0.8$ \\
\hline
\end{tabular}

\section{D BIOMECHANICAL MODEL}

To obtain hip and knee joint kinematic data, a total of 22 reflective markers were placed over anatomical landmarks according to a modified Helen Hayes marker setup, ${ }^{44}$ except for the thigh markers, which were substituted by markers attached over the patella, to reduce the effect of wobbling masses. ${ }^{45}$

\section{STATISTICAL ANALYSIS}

Shapiro-Wilk testing was performed to check for normality. Subsequently, a two-way analysis of variance (ANOVA) was performed in SPSS (Version 22, IBM SPSS Statistics) using a repeated measures procedure with Bonferroni corrections to determine whether differences existed in peak nEMG between exercise type and medial vs lateral hamstring muscles, respectively. Factors included in the model were muscles (ST and BF) and exercises (six exercises), as well as the interaction between these. Pearson correlation analysis was performed to examine the potential relationship between hip- and knee joint range of motion and muscle activity, respectively.

$p$-values of $\leqslant 0.05$ were considered statistically significant.

A statistical power of $80 \%$ to detect a difference of $\mathrm{p}=0.05$ with a standard deviation of 20 in nEMG (expressed in \% of peak EMG at MVC) and a between-exercise difference of $15 \%$ points of peak nEMG was calculated to require a total of 16 participants. ${ }^{33}$

\section{RESULTS}

Data were excluded from two participants, due to undetected loss of markers during the test exercises. Thus, the present results contain data from 21 participants. Subject characteristics are presented in Table 1 with participant flow illustrated in Figure 1.

\section{HAMSTRING MUSCLE ACTIVATION}

Total hamstring muscle activity (mean $(\mathrm{ST}+\mathrm{BF})$ ) expressed as peak normalized EMG amplitude (nEMG) varied between the different test exercises (Figure 3). The HT exercise performed at $110^{\circ}$ knee angle (HT $\left.110^{\circ}\right)$ showed the highest activity level of $68.9 \pm 16.6 \%$ (mean \pm SD). Hamstring activity levels for the other tested exercises were: Two-legs DL (DL-2legs) (68.0 $\pm 18.8 \%), \quad$ Single-leg HT (HT-1leg)

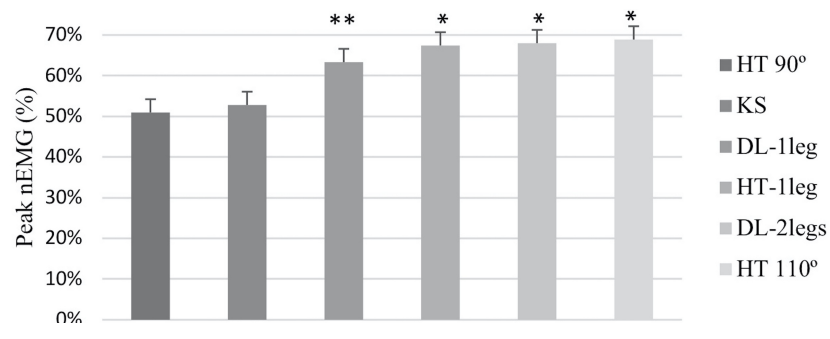

Figure 3: Mean hamstring activity (\% of peak nEMG) shown as group mean $+/$ - SEM.

*Significantly different from KS and HT $90^{\circ}(\mathrm{p}<0.02),{ }^{* *}$ Significantly different from $\mathrm{HT} 90^{\circ}(\mathrm{p}<0.02)$.

Table 2: Peak normalized EMG (nEMG) activity of ST and BF. Expressed as mean ( \pm SD).

\begin{tabular}{|l|c|c|}
\hline \multirow{2}{*}{ Exercises } & \multicolumn{2}{|c|}{ Peak nEMG (\% of max) } \\
\cline { 2 - 3 } & ST & BF \\
\hline DL-2legs & $80(17)$ & $57(20)^{* *}$ \\
DL-1leg & $74(16)$ & $54(18)^{* *}$ \\
KS & $59(14)$ & $47(16)^{* *}$ \\
HT 90 & $54(17)$ & $47(15)^{*}$ \\
HT 110 & $71(18)$ & $65(16)$ \\
HT-1leg & $69(18)$ & $66(18)$ \\
\hline
\end{tabular}

nEMG= normalized EMG, $\mathrm{ST}=$ semitendinosus, $\mathrm{BF}=$ biceps femoris, DL-2legs= two-legged deadlift, DL-1leg= single leg dead lift, KS= kettlebell swing, HT= hip thrust *Significant difference between ST and BF ( $\mathrm{p}=0.038)$.

**Significant difference between ST and BF $(\mathrm{p}<0.0001)$

(67.4 $\pm 18.3 \%)$, Single-leg DL (DL-1leg) $(63.6 \pm 16.7 \%)$, KS $(53.0 \pm 15.0 \%)$, HT performed at $90^{\circ}$ knee angle $\left(\mathrm{HT} 90^{\circ}\right)$ (50.4 $\pm 15.9 \%)$.

\section{MEDIAL VERSUS LATERAL HAMSTRING ACTIVITY}

ST and BF muscle activity assessed in each exercise are presented in Table 2. ST showed greater muscle activity compared to BF, except for HT-1leg ( $69 \pm 18 \%$ vs. $66 \pm 18 \%)$ and HT $110^{\circ}(71 \pm 18 \%$ vs. $65 \pm 16 \%)$. ST and BF activity levels for the other tested exercises were: DL-2legs $(80 \pm 17$ $\%$ vs. $57 \pm 20 \%$, p $<0.0001)$, DL-1leg $(74 \pm 16 \%$ vs. $54 \pm 18 \%$, $\mathrm{p}<0.0001)$, KS $(59 \pm 14 \%$ vs. $47 \pm 16 \%, \mathrm{p}<0.0001)$, HT $90^{\circ}$ ( $54 \pm 17 \%$ vs. $47 \pm 15 \%$, p=0.038). 


\section{MEDIO-LATERAL ACTIVATION BALANCE}

Within-exercise analysis of the medial-lateral hamstring activation balance $(\Delta=$ difference between ST and BF, \pm SD) showed a preferential activation of ST over BF during DL-2legs $(\Delta 23.8 \pm 2.4 \%$, p $<0.0001)$, DL-1leg $(\Delta 20.0 \pm 2.2 \%$, $\mathrm{p}<0.0001)$, KS $(\Delta 12.8 \pm 2.1 \%, \mathrm{p}<0.0001)$ and HT $110^{\circ}$ $(\Delta 6.5 \pm 2.1 \%, \mathrm{p}<0.05)$, whereas no difference was found for HT $90^{\circ}(\Delta 6.3 \pm 2.3 \%)$ and HT-1leg $(\Delta 2.1 \pm 1.0 \%$ ) (Figure 4 , bar graphs).

Between exercise analysis of the medial-lateral activation balance (Figure 4, arrows) revealed elevated muscle activity difference in favor of ST during DL-2legs compared to KS ( $\triangle 11 \%)$, HT $110^{\circ}(\sim \Delta 17.3 \%)$, HT $90^{\circ}(\sim \Delta 17.5 \%)$ and HT-1leg $(\sim \Delta 21.7 \%)(\mathrm{p}<0.0001)$. Likewise, DL-1leg evoked greater ST-BF activity difference than HT $110^{\circ}(\sim \Delta 13.5 \%)$, HT $90^{\circ}(\sim \Delta 13.7 \%)$ and HT-1leg $(\sim \Delta 17.9 \%)(\mathrm{p}<0.001)$. ST$\mathrm{BF}$ muscle activity difference was also greater during the KS compared to HT-1leg $(\sim \Delta 10.7 \%)(\mathrm{p}<0.01)$.

\section{RELATIONSHIPS BETWEEN HAMSTRING MUSCLE ACTIVITY AND KNEE JOINT ROM}

For the HT exercises, HT $110^{\circ}$ demonstrated a knee range of motion (ROM) between $79.9 \pm 9.2^{\circ}$ and $56.8^{ \pm 9.7^{\circ}}$ flexion. HT $90^{\circ}$ had a knee ROM between $102.2^{ \pm 9.9^{\circ}}$ and $76.1 \pm 10.2^{\circ}$ flexion. A correlation analysis revealed a positive correlation $(r=0.515, \mathrm{p}<0.035)$ between more extended knee joint angles and increased ST and BF muscle activity.

The KS exercise was characterized by a hip ROM ranging from $2.4 \pm 8.2^{\circ}$ to $96.5 \pm 8.0^{\circ}$ of flexion whereas knee ROM was $9.5 \pm 5.5^{\circ}$ to $48.2^{ \pm} 11.5^{\circ}$ flexion $\left(0^{\circ}=\right.$ full extension $)$. A positive correlation was revealed $(r=0.436, \mathrm{p}<0.024)$ between more extended knee joint angles and increased ST muscle activity during the ECC phase.

The DL exercises demonstrated a hip ROM between $9.7 \pm 5.9^{\circ}$ and $100.2 \pm 7.5^{\circ}$ flexion, and a knee ROM between $8.4^{ \pm 6.2^{\circ}}$ and $34.8 \pm 9.7^{\circ}$ flexion. No correlation was observed between DL kinematics versus ST or BF muscle activity.

\section{RELATIONSHIP BETWEEN HAMSTRING MUSCLE ACTIVITY AND HIP EXTENSION ANGULAR VELOCITY}

The KS exercise demonstrated a mean hip extension angular velocity (HAV) of $312.2 \pm 58.1^{\circ} \mathrm{s}^{-1}$ and $204.2 \pm 40.2^{\circ} \mathrm{s}^{-1}$ in the CON- and ECC phase, respectively. A positive correlation was revealed $(r=0.459, \mathrm{p}<0.05)$ between increased HAV and elevated ST muscle activity.

The DL exercises performed on either two legs or a single leg demonstrated a mean HAV of $244.8 \pm 37.1^{\circ} \mathrm{s}^{-1}$ and $203.8 \pm 32.3^{\circ} \mathrm{s}^{-1}$, respectively, in the CON phase. Velocity in the ECC phase was $101.2 \pm 36.2^{\circ} \mathrm{s}^{-1}$ when performed on two legs and $71.6 \pm 21.9^{\circ} \mathrm{s}^{-1}$ on a single leg. No relationships were observed between HAV in both DL exercises and hamstring activity.

The HT exercises demonstrated a mean CON HAV of $222.7 \pm 54.8^{\circ} \mathrm{s}^{-1}, 201.3 \pm 49.8^{\circ} \mathrm{s}^{-1}$ and $157.3 \pm 39.7^{\circ} \mathrm{s}^{-1}$ in HT $90^{\circ}$, HT $110^{\circ}$ and HT-1leg, respectively. The ECC phase demonstrated a mean HAV of $93.2 \pm 39.0^{\circ} \mathrm{s}^{-1}, 89.9 \pm 27.9^{\circ} \mathrm{s}^{-1}$ and $81.2 \pm 20.5^{\circ} \mathrm{s}^{-1}$ in HT $90^{\circ}$, HT $110^{\circ}$ and HT-1leg, respectively. No relationships were observed between HAV in all

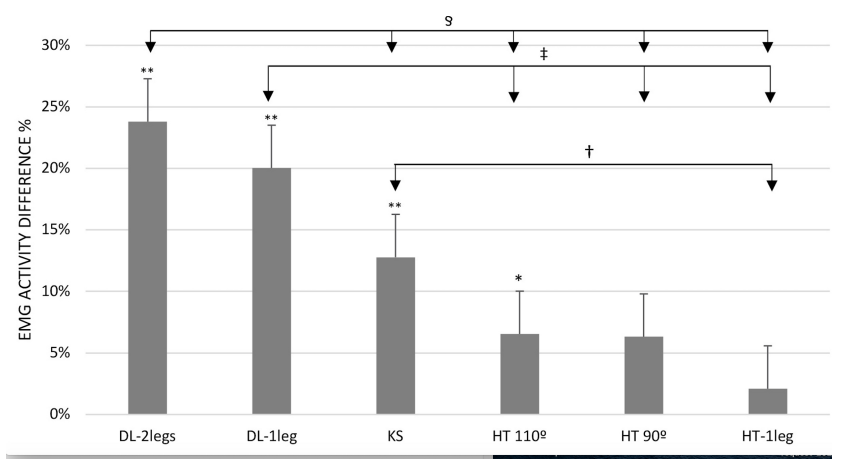

\section{Figure 4: Medial-lateral hamstring activation} balance presented as group mean +/-SEM.

"Significant difference in activation of the ST over the BF in each exercise ( $\mathrm{p}<$ $0.05)$. ** Significant difference in activation of the ST over the BF in each exercise $(p<0.0001)$. $†$ Significantly different from HT-1leg in activation of the ST over the BF ( $p<0.01)$. $\ddagger$ Significantly different from HT-1let, HT 110 and $90^{\circ}$ in activation of the ST over the BF ( $p<0.001)$. § Significantly different from KS, HT-1leg, 110 and $90^{\circ}$ in activation of the ST over the BF ( $\left.p<0.0001\right)$.

HT exercises and hamstring activity.

A comparison analysis between exercises showed higher CON HAV in KS compared to both DL exercises and the three HT exercises $(\mathrm{p}<0.035)$. Likewise, DL-2legs showed higher HAV compared to DL-1leg, HT $110^{\circ}$ and HT-1leg ( $<<0.023)$. Finally, DL-1leg, HT $90^{\circ}$ and HT $110^{\circ}$ showed higher HAV compared to HT-1leg $(\mathrm{p}<0.045)$. KS showed higher HAV compared to all the other exercises in the ECC phase $(\mathrm{p}<0.034)$.

\section{DISCUSSION}

The main finding of the present study was that all examined lower limb exercises elicited a minimum of $50 \%$ muscle activity in the hamstring muscles, which identified these exercises to be suitable for hamstring muscle strengthening. Further, the majority of the exercises were ST dominant, as evident by elevated ST compared to BF muscle activity. HT and KS displayed a positive correlation between more extended knee joint angles and elevated ST muscle activity. Likewise, KS revealed a positive correlation between increased HAV and an increase in ST muscle activity.

\section{HAMSTRING MUSCLE ACTIVATION}

All exercises involved high levels of muscle activity in the hamstring muscles, especially when knee joint angles were near full extension $\left(180^{\circ}=\right.$ full extension). In the HT exercise, a positive correlation also was found between reaching more extended knee joint angles and elevated ST and BF activity. Similar observations have been reported by Collazo Garcia et al., ${ }^{43}$ who tested four variations of the HT exercise, two of those similar to the HT $90^{\circ}$ and HT $110^{\circ}$ in the present study. ${ }^{43}$ Their study revealed high levels of ST and BF activity when HT exercise was performed with a more extended knee joint angle (ST: $70 \pm 17 \%$ vs $71 \pm 18 \%$ in the present study) compared to a $90^{\circ}$ knee joint angle (ST: $32 \pm 8 \%$ vs $54 \pm 17 \%$ in the present study). The architecture of the ST muscle with long fiber lengths gives it excellent potential to contract at long muscle lengths. ${ }^{33}$ This could at least in part 
explain the lower muscle activation differences between ST and $\mathrm{BF}$ at more extended knee joint angles observed in both the Collazo Garcia and the present study.

Together with $\mathrm{HT} 90^{\circ}$, the KS exercise demonstrated the lowest levels of hamstring muscle activity. Previous studies have reported similar magnitudes of normalized muscle activity in the KS exercise. ${ }^{46-48}$ In contrast, a single previous study observed hamstring activity levels in KS reaching $90 \%$ of $\mathrm{nEMG}$, which was recorded at $7 \pm 8^{\circ}$ knee joint flexion. ${ }^{33}$ This is in contrast to the present study, which demonstrated a mean knee joint ROM between $10.7 \pm 4.1^{\circ}$ and $48.2 \pm 11.2^{\circ}$ flexion (mean for KS: $30.9 \pm 6.7^{\circ}$ ). Furthermore, the present study revealed a positive correlation between more extended knee joint angles and increased hamstring muscle activity in the KS exercise. Even though Zebis and coworkers used a similar setup and study population, the more extended knee joint angles in their study could possibly explain the high hamstring activity values observed in their study. 30

\section{ST-DOMINANT EXERCISES}

The present study revealed that DL and KS exercises preferentially activated ST over BF, and at intensity levels sufficient to stimulate muscle strength gains. Likewise, Zebis and coworkers reported DL-2legs and KS to be highly ST dominant exercises. ${ }^{33}$ During KS and DL, the hamstring muscles are extensively stretched with the highest load at the greatest hip flexion angles. Thus, the ST dominance may partly be explained by the fact that ST, in contrast to BF, are parallel fibered and characterized by long fiber lengths and a high number of sarcomeres in-series. ${ }^{49}$ This arrangement results in a large total shortening capacity (i.e. ensures large joint ROM) along with a high maximum velocity of contraction. ${ }^{50,51}$ Even though the KS may be superior to DL in reflecting real life sports activities due to its functional execution, our study clearly demonstrates that when DL is performed explosively using either a single leg or two legs, it evokes high preferential activation of the ST muscle.

\section{UNILATERAL EXERCISES}

Although the present study did not find a difference in the medial-lateral hamstring activation levels between bilateral and unilateral DL exercises, as a novel observation the present data indicated unilateral DL to involve high ST muscle activity while incorporating an important element of postural balance control. This may be relevant to consider in rehabilitative and prophylactic hip and knee stability training planning.

To the authors' best knowledge only two studies have previously examined hamstring muscle activity during single-leg DL exercise. ${ }^{48,52}$ Examining female athletes, Tsaklis and coworkers reported higher ST muscle activity compared to BF during DL-1leg, 48 even though muscle activity levels per se were lower compared to the present study. The fact that DL-1leg is a ST dominant exercise, despite low exercise loads, ${ }^{48}$ indicates that it may be relevant to implement this exercise in early rehabilitation after ACL reconstruction, where high exercise loads are contraindicated.

No previous studies have examined hamstring muscle activity during unilateral HT, however, neuromuscular activity has been assessed in various lower limb muscles including the hamstrings during different bridge exercises using a single leg. ${ }^{53-55}$ The bridge exercise is comparable to the HT, but the shoulders are supported on the floor instead of a bench, while still involving extension of the hip. When ST muscle activity was examined during single-leg bridge exercise performed with different knee joint angles, higher ST muscle activity was noted between $90^{\circ}(57 \pm 31 \%)$ and $60^{\circ}(79 \pm 32 \%)$ compared to the $120^{\circ}(19 \pm 12 \%)$ knee joint flexion. ${ }^{54}$ Similar activity levels were noted in the Lehecka study for the BF muscle $(69 \pm 18 \%)$, which more or less is comparable to the results from the present study (ST: $69 \pm 18$ $\%$ and BF: $66 \pm 18 \%$ ).

Unilateral HT exercise revealed significantly lower HAV compared to bilateral HT, KS and DL exercises. Furthermore, unilateral HT demonstrated the smallest medial-lateral hamstring activation difference. In the execution of this exercise, stability around the hip and core is essential for ensuring a stable (i.e. non-tilting) pelvis. This weight shifting caused by the unilateral execution of the exercise might have caused a more equal medial to lateral activation. Notably, unilateral HT did not seem to be effective of elevating ST muscle activity over BF. However, this exercise could be preferable when focusing on improving hip and core stability, as well as eliciting high overall hamstring muscle activity, without increasing direct load on the knee joint.

\section{LIMITATIONS}

During the process of off-line data analysis, a number of participants demonstrated knee joint flexion angles in the KS that were more flexed $\left(\sim 25-30^{\circ}\right)$ than the target position of $15^{\circ}$, which were not readily apparent during the time of testing. Furthermore, as this study evaluated selected lower limb training exercises among female athletes, the present findings and conclusions may not be readily transferable to male athletes or untrained persons.

\section{CONCLUSIONS}

In conclusion, the present study identified a number of lower limb strength exercises with high levels of neuromuscular activity in the hamstring muscles. As the main study finding, all these exercises involved higher ST activity over BF. Equally important, unilateral as well as bilateral DL exercises showed the greatest medial-lateral activation difference favoring ST activation compared to all other exercises.

The kinematic data furthermore illustrate that ensuring extended knee joint angles and increasing HAV may be key focus areas for health care professionals and physical conditioning coaches, and these aspects may be more challenging to achieve during explosive-type exercise such as the KS.

\section{CONFLICTS OF INTEREST AND SOURCE OF FUNDING}

The authors report no conflicts of interest and no source of 
funding.

CDT

Submitted: August 28, 2020 CDT, Accepted: February 18, 2021

This is an open-access article distributed under the terms of the Creative Commons Attribution 4.0 International License (CCBY-NC-SA-4.0). View this license's legal deed at https://creativecommons.org/licenses/by-nc-sa/4.0 and legal code at https://creativecommons.org/licenses/by-nc-sa/4.0/legalcode for more information. 


\section{REFERENCES}

1. Øiestad BE, Holm I, Aune AK, et al. Knee Function and Prevalence of Knee Osteoarthritis after Anterior Cruciate Ligament Reconstruction:A Prospective Study with 10 to 15 Years of Follow-up. Am J Sports Med. 2010;38(11):2201-2210. doi:10.1177/036354651 $\underline{0373876}$

2. Ajuied A, Wong F, Smith C, et al. Anterior cruciate ligament injury and radiologic progression of knee osteoarthritis: A systematic review and metaanalysis. Am J Sports Med. 2014;42(9):2242-2252. do i: $10.1177 / 0363546513508376$

3. Myklebust G, Engebretsen L, Braekken IH, Skjolberg A, Olsen OE, Bahr R. Prevention of anterior cruciate ligament injuries in female team handball players: A prospective intervention study over three seasons. Clin J Sport Med. 2003;13(2):71-78.

4. Sepulveda F, Sanchez L, Amy E, Micheo W. Anterior cruciate ligament injury: Return to play, function and long-term considerations. Curr Sports Med Rep. 2017;16(3):172-178. doi:10.1249/jsr.00000000000003 $\underline{56}$

5. Jakobsen BW. Knæleddets idrætsrelaterede skader. Idrætsskadebogen. 2007;1:369-400.

6. Ristic V, Ninkovic S, Harhaji V, Milankov M. Causes of anterior cruciate ligament injuries. Med Pregl. 2010;63(7-8):541-545.

7. Vauhnik R, Morrissey MC, Rutherford OM, Turk Z, Pilih IA, Perme MP. Rate and risk of anterior cruciate ligament injury among sportswomen in Slovenia. J Athl Train. 2011;46(1):92-98. doi:10.4085/1062-605 $\underline{0-46.1 .92}$

8. Myklebust G, Maehlum S, Engebretsen L, Strand T, Solheim E. Registration of cruciate ligament injuries in Norwegian top level team handball. A prospective study covering two seasons. Scand J Med Sci Sports. 1997;7(5):289-292.

9. Yoo JH, Lim BO, Ha M, et al. A meta-analysis of the effect of neuromuscular training on the prevention of the anterior cruciate ligament injury in female athletes. Knee Surg Sports Traumatol Arthrosc. 2010;18(6):824-830. doi:10.1007/s00167-009-0901-2

10. Bjordal JM, Arnly F, Hannestad B, Strand T. Epidemiology of anterior cruciate ligament injuries in soccer. Am J Sports Med. 1997;25(3):341-345. doi:10.1 177/036354659702500312
11. Boden BP, Sheehan FT, Torg JS, Hewett TE. Noncontact anterior cruciate ligament injuries: mechanisms and risk factors. J Am Acad Orthop Surg. 2010;18(9):520-527.

12. Ireland ML, Ott SM. Special concerns of the female athlete. Clin Sports Med. 2004;23(2):281-298. $\underline{\mathrm{d}}$ oi:10.1016/j.csm.2004.04.003

13. Allen MM, Pareek A, Krych AJ, et al. Are female soccer players at an increased risk of second anterior cruciate ligament injury compared with their athletic peers? Am J Sports Med. 2016;44(10):2492-2498. doi:1 $\underline{0.1177 / 0363546516648439}$

14. Chappell JD, Creighton RA, Giuliani C, Yu B, Garrett WE. Kinematics and electromyography of landing preparation in vertical stop-jump: risks for noncontact anterior cruciate ligament injury. Am J Sports Med. 2007;35(2):235-241. doi:10.1177/0363546 $\underline{506294077}$

15. Hanson AM, Padua DA, Troy Blackburn J, Prentice WE, Hirth CJ. Muscle activation during side-step cutting maneuvers in male and female soccer athletes. J Athl Train. 2008;43(2):133-143. doi:10.408 5/1062-6050-43.2.133

16. Sigward SM, Powers CM. The influence of gender on knee kinematics, kinetics and muscle activation patterns during side-step cutting. Clin Biomech. 2006;21(1):41-48. doi:10.1016/i.clinbiomech.2005.0 $\underline{8.001}$

17. Bencke J, Zebis MK. The influence of gender on neuromuscular pre-activity during side-cutting. $J$ Electromyogr Kinesiol. 2011;21(2):371-375. doi:10.101 6/j.jelekin.2010.10.008

18. Malinzak RA, Colby SM, Kirkendall DT, Yu B, Garrett WE. A comparison of knee joint motion patterns between men and women in selected athletic tasks. Clin Biomech. 2001;16(5):438-445. doi:10.1016/ $\underline{\mathrm{s} 0268-0033(01) 00019-5}$

19. Urabe Y, Kobayashi R, Sumida S, et al. Electromyographic analysis of the knee during jump landing in male and female athletes. The Knee. 2005;12(2):129-134. doi:10.1016/j.knee.2004.05.002

20. De Britto MA, Carpes FP, Koutras G, Pappas E. Quadriceps and hamstrings prelanding myoelectric activity during landing from different heights among male and female athletes. J Electromyogr Kinesiol. 2014;24(4):508-512. doi:10.1016/i.jelekin.2014.04.009 
21. Ebben W, Leigh D, Long N, et al.

Electromyographical analysis of hamstring resistance training exercises. Sports Biomech, XXIV International Symposium on Biomechanics in Sports 2006, Salzburg, Austria, University of Salzburg. 2006:236-239.

22. Zebis MK, Bencke J, Andersen LL, et al. The effects of neuromuscular training on knee joint motor control during sidecutting in female elite soccer and handball players. Clin J Sport Med. 2008;18(4):329-337. doi:10.1097/ISM.0b013e31817f3e $\underline{35}$

23. Alentorn-Geli E, Myer GD, Silvers HJ, et al. Prevention of non-contact anterior cruciate ligament injuries in soccer players. Part 1: Mechanisms of injury and underlying risk factors. Knee Surg Sports Traumatol Arthrosc. 2009;17(7):705-729. doi:10.1007/ s00167-009-0813-1

24. Alentorn-Geli E, Myer GD, Silvers HJ, et al. Prevention of non-contact anterior cruciate ligament injuries in soccer players. Part 2: a review of prevention programs aimed to modify risk factors and to reduce injury rates. Knee Surg Sports Traumatol Arthrosc. 2009;17(8):859-879. doi:10.1007/s00167-00 9-0823-Z

25. Zebis MK, Andersen LL, Bencke J, Kjaer M, Aagaard P. Identification of athletes at future risk of anterior cruciate ligament ruptures by neuromuscular screening. Am J Sports Med. 2009;37(10):1967-1973. d oi: $10.1177 / 0363546509335000$

26. Hewett TE, Myer GD, Ford KR, et al. Biomechanical measures of neuromuscular control and valgus loading of the knee predict anterior cruciate ligament injury risk in female athletes: a prospective study. Am J Sports Med. 2005;33(4):492-501. doi:10.1177/0363546504269591

27. Bencke J, Aagaard P, Zebis MK. Muscle activation during ACL injury risk movements in young female athletes: A narrative review. Front Physiol. 2018;9:445. doi:10.3389/fphys.2018.00445

28. Rozzi SL, Lephart SM, Gear WS, Fu FH. Knee joint laxity and neuromuscular characteristics of male and female soccer and basketball players. Am J Sports Med. 1999;27(3):312-319. doi:10.1177/03635465990270030 801

29. Andersen LL, Magnusson SP, Nielsen M, Haleem J, Poulsen K, Aagaard P. Neuromuscular activation in conventional therapeutic exercises and heavy resistance exercises: implications for rehabilitation. Phys Ther. 2006;86(5):683-697.
30. Dedinsky R, Baker L, Imbus S, Bowman M, Murray L. Exercises that facilitate optimal hamstring and quadriceps co-activation to help decrease ACL injury risk in healthy females: A systematic review of the literature. Int J Sports Phys Ther. 2017;12(1):3-15.

31. Khaiyat OA, Norris J. Electromyographic activity of selected trunk, core, and thigh muscles in commonly used exercises for ACL rehabilitation. $J$ Phys Ther Sci. 2018;30(4):642-648. doi:10.1589/jpts.3 $\underline{0.642}$

32. Wilk KE, Escamilla RF, Fleisig GS, Barrentine SW, Andrews JR, Boyd ML. A comparison of tibiofemoral joint forces and electromyographic activity during open and closed kinetic chain exercises. Am J Sports Med. 1996;24(4):518-527. doi:10.1177/0363546596024 $\underline{00418}$

33. Zebis MK, Skotte J, Andersen CH, et al. Kettlebell swing targets semitendinosus and supine leg curl targets biceps femoris: an EMG study with rehabilitation implications. Br J Sports Med. 2013;47(18):1192-1198. doi:10.1136/bjsports-2011-09 $\underline{0281}$

34. Beardsley C, Contreras BM. The role of kettlebells in strength and conditioning: A review of the literature. Strength Cond J. 2014;36(3):64-70.

35. Brumitt I, En Gilpin H, Brunette M, Meira EP. Incorporating kettlebells into a lower extremity sports rehabilitation program. $N$ Am J Sports Phys Ther. 2010;5(4):257-265.

36. Lake JP, Lauder MA. Kettlebell swing training improves maximal and explosive strength. J Strength Cond Res. 2012;26(8):2228-2233. doi:10.1519/ISC.0b0 $13 \mathrm{e} 31825 \mathrm{c} 2 \mathrm{c} 9 \mathrm{~b}$

37. Lephart SM, Abt JP, Ferris CM, et al.

Neuromuscular and biomechanical characteristic changes in high school athletes: a plyometric versus basic resistance program. $\mathrm{Br} J$ Sports Med. 2005;39(12):932-938.

38. Otto WH III, Coburn JW, Brown LE, Spiering BA. Effects of weightlifting vs. kettlebell training on vertical jump, strength, and body composition. $J$ Strength Cond Res. 2012;26(5):1199-1202. doi:10.151 9/ISC.0b013e31824f233e

39. Walden M, Atroshi I, Magnusson H, Wagner P, Hagglund M. Prevention of acute knee injuries in adolescent female football players: cluster randomised controlled trial. $\mathrm{Br}$ Med $\mathrm{J}$. 2012;344:e3042. doi:10.1136/bmi.e3042 
40. Zebis MK, Andersen CH, Bencke J, et al. Neuromuscular coordination deficit persists 12 months after ACL reconstruction but can be modulated by 6 weeks of kettlebell training: A case study in women's elite soccer. J Orthop Case Rep. 2017;2017:4269575. doi:10.1155/2017/4269575

41. Zebis MK, Andersen LL, Brandt M, et al. Effects of evidence-based prevention training on neuromuscular and biomechanical risk factors for ACL injury in adolescent female athletes: a randomised controlled trial. Br J Sports Med. 2016;50(9):552-557. doi:10.1136/bjsports-2015-09477 $\underline{6}$

42. Hermens HJ, Freriks B, Disselhorst-Klug C, Rau G. Development of recommendations for SEMG sensors and sensor placement procedures. J Electromyogr Kinesiol. 2000;10(5):361-374. doi:10.1016/S1050-641 1(00)00027-4

43. Collazo Garcia CL, Rueda J, Suarez Luginick B, Navarro E. Differences in the electromyographic activity of lower-body muscles in hip thrust variations. J Strength Cond Res. 2018. doi:10.1519/js c.0000000000002859

44. Kadaba MP, Ramakrishnan HK, Wootten ME. Measurement of lower extremity kinematics during level walking. J Orthop Res. 1990;8(3):383-392. doi:1 $\underline{0.1002 / j o r .1100080310}$

45. Wren TA, Do KP, Hara R, Rethlefsen SA. Use of a patella marker to improve tracking of dynamic hip rotation range of motion. Gait Posture. 2008;27(3):530-534. doi:10.1016/j.gaitpost.2007.07.00 6

46. Del Monte MJ, Opar DA, Timmins RG, Ross J, Keogh JW, Lorenzen C. Hamstring myoelectrical activity during three different kettlebell swing exercises. J Strength Cond Res. 2017. doi:10.1519/jsc.0 $\underline{000000000002254}$
47. Lyons BC, Mayo JJ, Tucker WS, Wax B, Hendrix RC. Electromyographical comparison of muscle activation patterns across three commonly performed kettlebell exercises. J Strength Cond Res. 2017;31(9):2363-2370. doi:10.1519/jsc.0000000000001771

48. Tsaklis P, Malliaropoulos N, Mendiguchia J, et al. Muscle and intensity based hamstring exercise classification in elite female track and field athletes: implications for exercise selection during rehabilitation. Open Access J Sports Med. 2015;6:209-217. doi:10.2147/oajsm.S79189

49. Berne RM, Levy MN. Principles of physiology. Skeletal Muscle. 2000;3:818.

50. Kraemer WJ, Adams K, Cafarelli E, et al. American College of Sports Medicine position stand. Progression models in resistance training for healthy adults. Med Sci Sports Exerc. 2002;34(2):364-380.

51. Levy M, Koeppen B, Stanton B. Berne \& Levy Principles of Physiology. 4th ed. Mosby; 2005.

52. Lynn SK, Costigan PA. Changes in the mediallateral hamstring activation ratio with foot rotation during lower limb exercise. J Electromyogr Kinesiol. 2009;19(3):197-205. doi:10.1016/j.jelekin.2008.01.007

53. Ekstrom RA, Donatelli RA, Carp KC. Electromyographic analysis of core trunk, hip, and thigh muscles during 9 rehabilitation exercises. $J$ Orthop Sports Phys Ther. 2007;37(12):754-762. doi:1 0.2519/jospt.2007.2471

54. Kim J, Park M. Changes in the activity of trunk and hip extensor muscles during bridge exercises with variations in unilateral knee joint angle. J Phys Ther Sci. 2016;28(9):2537-2540. doi:10.1589/jpts.28.2537

55. Lehecka BJ, Edwards M, Haverkamp R, et al. Building a better gluteal bridge: Electromyographic analysis of hip muscle activity during modified single-leg bridges. Int J Sports Phys Ther. 2017;12(4):543-549. 